\title{
Spontaneous Dissections of the Carotid Arteries in a Patient with Recent Coronary Artery Dissection
}

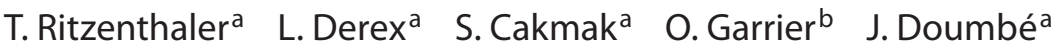 \\ N. Nighoghossian ${ }^{a} \quad$ P. Trouillas ${ }^{a}$

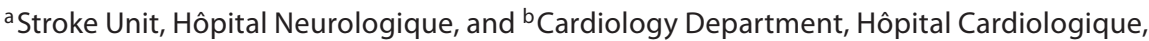 \\ University of Lyon, Lyon, France
}

\section{Dear Sir,}

Multiple dissections of the carotid and coronary arteries are exceptional [1]. We report the case of a young woman without known hereditary connective tissue disorder who presented with spontaneous dissection of the left anterior descending coronary artery, followed by spontaneous dissection of both internal carotid arteries (ICA) 3 weeks later. We discuss the pathogenesis of these multiple dissections.

\section{Case Report}

A 44-year-old right-handed woman was admitted to the University of Lyon stroke unit on June 27, 2006, because of a right hemiparesis with aphasia which were present on awakening. Vascular risk factors were limited to obesity (body mass index $=32$ ). The medical history revealed anterior wall myocardial infarction related to spontaneous dissection of the left anterior descending artery 3 weeks before, confirmed by a coronary angiography (fig. 1). She had been treated by coronary angioplasty with a drug-eluting stent (taxus) and had been discharged from the cardiological intensive-care unit under clopidogrel $75 \mathrm{mg}$ daily, aspirin $75 \mathrm{mg}$ daily, bisoprolol $1.25 \mathrm{mg}$ twice daily, ramipril 2.5 $\mathrm{mg}$ twice daily, eplerenon $25 \mathrm{mg}$ daily and pravastatin $20 \mathrm{mg}$ daily. Post-myocardialinfarction echocardiography had demonstrated anteroseptoapical hypokinesia with low left ventricular ejection fraction (50\%). On admission, right hemiparesis and aphasia had cleared. The patient had no history of recent infection (no fever, no flu, no respiratory tract symptoms) and reported no prior transient neurological deficit, headache or cervical pain. No Horner's syndrome was observed. The patient had no skin, joint, eye or skeletal abnormalities suggesting a hereditary connective tissue disorder. No family history of arterial dissection or valvular heart disease was noted. Multimodal MRI performed on June 27 showed no recent ischemic lesion on diffusion-weighted imaging. $T_{2}$-weighted sequences showed bilateral middle cerebral artery/anterior cerebral artery borderzone hyperintensities. Magnetic resonance angiography showed occlusion of the right ICA beginning $1 \mathrm{~cm}$ after the bifurcation and narrow stenosis of the left ICA in the subpetrous segment consistent with the diagnosis of bilateral spontaneous ICA dissection (fig. 2). Collateral supply was efficient through the right posterior communicating artery. No intramural hematoma was observed. No angiographic changes of fibromuscular dysplasia were found. Neck ultrasound was suggestive of right ICA occlusion and left distal ICA stenosis. Right ophthalmic artery flow was reversed. Vertebral arteries were normal with increased compensatory flow. Erythrocyte sedimentation rate and $\mathrm{C}$-reactive protein level were normal. Intravenous unfractionated heparin $(18,000$ IU daily aiming at doubling the partial thromboplastin time) was started on June 28 substituted with oral anticoagulation therapy (acenocoumarol $3 \mathrm{mg}$ daily with a target international normalized ratio of 2.0-3.0) on July 4. Control transthoracic and transesophageal echocardiography performed on July 3 showed no persistent hypokinesia. Left ventricular ejection fraction had returned to normal (68\%). No aortic arch atheroma was observed. Aortic root diameter was $35 \mathrm{~mm}$. Grade $1 \mathrm{mi}-$ tral valve insufficiency was present. The patient was discharged from the stroke unit on July 6 . The clinical follow-up at 4 months showed normal neurological examination. No recurrent cardiac or cerebral ischemic event had occurred. Control MRI at 4 months showed no recent ischemic lesion and the persistence of the right ICA occlusion while the left ICA had returned to normal (fig. 3). Oral anticoagulation therapy was stopped whereas dual antiplatelet therapy (clopidogrel

\section{KARGER}

Fax +4161306 1234 E-Mail karger@karger.ch www.karger.com (c) 2008 S. Karger AG, Base 0014-3022/08/0596-0324\$24.50/0

Accessible online at: www.karger.com/ene
Dr. Laurent Derex

Unité Neurovasculaire

Hôpital Neurologique, 59, boulevard Pinel

FR-69003 Lyon (France)

Tel. +33 47235 7806, Fax +3347235 7329, E-Mail laurent.derex@chu-lyon.fr 


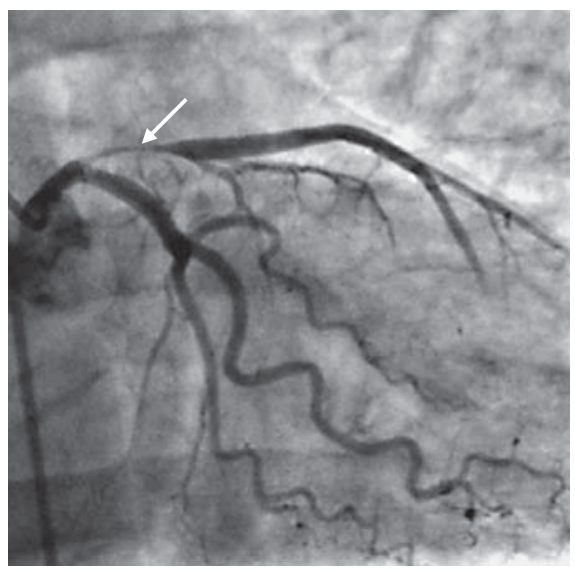

Fig. 1. Coronary angiography showing dissection of the left anterior descending artery (arrow).

$75 \mathrm{mg}$ daily and aspirin $75 \mathrm{mg}$ daily) was maintained in order to prevent coronary stent thrombosis.

\section{Discussion}

Spontaneous dissections of the carotid and vertebral arteries account for $10-25 \%$ of ischemic stroke in young and middleaged patients [2]. Most dissections are 'spontaneous' while minor or 'trivial' traumas are observed in approximately $40 \%$ of cases [3]. Patients with spontaneous carotid dissection are thought to have an underlying structural defect of the arterial wall, although only a minority present a wellcharacterized heritable connective tissue disorder (Marfan's syndrome, Ehlers-Danlos syndrome type IV, autosomal dominant polycystic kidney disease or osteogenesis imperfecta type I).

We considered that the prior medical history and the MRI data (location and aspect of carotid abnormalities on baseline imaging, recanalization of the left ICA on follow-up imaging) were suggestive of bilateral carotid dissection. The absence of a visible intramural hematoma in our patient may be related to the timing of MRI (the exact time of onset of the carotid artery dissections after the initial coronary

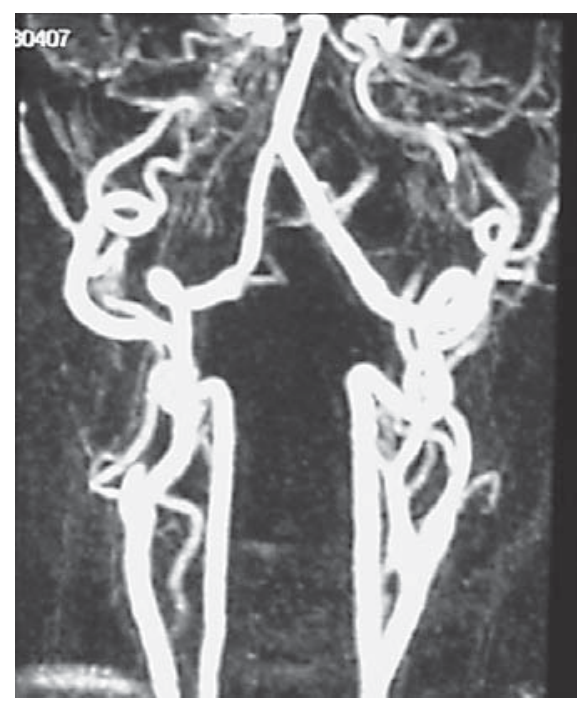

Fig. 2. Baseline magnetic resonance angiography showing occlusion of the right ICA and narrow stenosis of the left ICA in the subpetrous segment.

artery dissection is unknown and the intramural hematoma may have disappeared). Bilateral cardiac embolism into both carotid arteries seems unlikely. To our knowledge, the association of carotid and coronary artery dissection has only been reported once [1]. On the other hand, there have been reports of dissections of the aorta [4] or of the renal arteries in patients with previous spontaneous carotid dissections, usually in the setting of fibromuscular dysplasia when both carotid and renal arteries are involved $[5,6]$.

Spontaneous coronary artery dissection is a rare cause of acute coronary syndrome. Most of the cases occur in young or middle-aged women (80\%) without vascular risk factors, especially during the peripartum period. The left anterior descending artery and left main coronary artery are most frequently involved (47 and 17\%, respectively). The outcome is considered grim, with a rate of survival as low as $33 \%$ of patients [7].

The involvement of coronary and carotid arteries in a short time (3 weeks), which was observed in our patient, points to a 'systemic' etiology. Our patient had no history of recent infection, and all markers of inflammation were normal. She denied any use of vasoconstricting or illicit drugs. She also had no history and no clin-

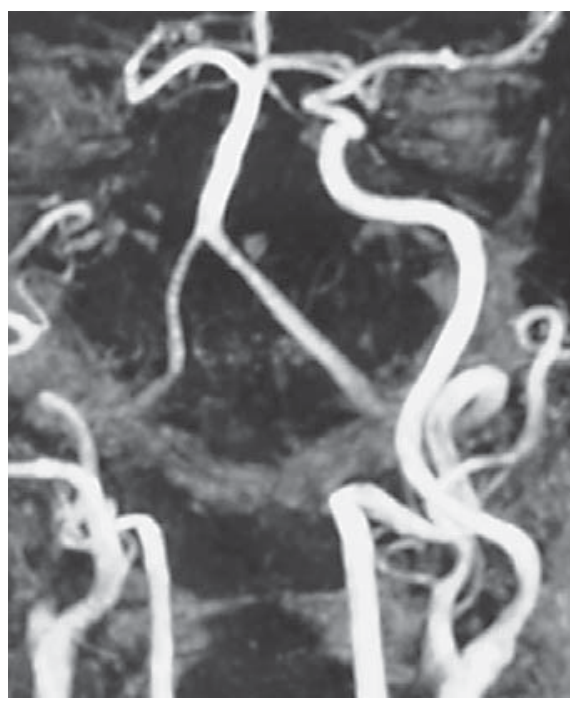

Fig. 3. Control magnetic resonance angiography at 4 months showing the persistence of the right ICA occlusion while the left ICA has returned to normal.

ical signs of hereditary connective tissue disorder. We hypothesize that our patient may suffer from a primary generalized arteriopathy related to an unknown connective tissue disorder that predisposes to structural weakness of the vessel wall and therefore increases the risk of dissection. The morphology of connective tissue elements was found to be aberrant in the majority of skin biopsies from patients with spontaneous cervical artery dissection lacking clinical stigmata of a known connective tissue disorder, pointing to a molecular defect in the biosynthesis of the extracellular matrix [8]. Our patient had evidence of an enlarged aortic root (35 mm) on transesophageal echocardiography, consistent with the existence of a generalized defect of the extracellular matrix. A case-control study has suggested that aortic root diameter enlargement (i.e. diameter $>34 \mathrm{~mm}$ ) is associated with an increased risk of spontaneous cervical artery dissection and that mitral and aortic valve dystrophy and mitral valve prolapse are more frequent in patients with spontaneous cervical artery dissection [9]. Our case report reinforces the concept of the presence of a generalized defect of the extracellular matrix in some patients presenting spontaneous cervical artery dissection. 


\section{References}

1 Censori B, Agostinis C, Partziguian T, Guagliumi G, Bonaldi G, Poloni M: Spontaneous dissection of carotid and coronary arteries. Neurology 2004;63:1122-1123.

-2 Schievink W: Spontaneous dissection of the carotid and vertebral arteries. N Engl J Med 2001;344:898-906.

3 Guillon B, Levy C, Bousser MG: Internal carotid artery dissection: an update. J Neurol Sci 1998;53:146-158.
4 Schievink WI, Mokri B: Aortic dissection decades following internal carotid artery dissection. Report of two cases. Angiology 1997;48:985-988.

5 Mokri B, Stanson AW, Houser OW: Spontaneous dissection of the renal arteries in a patient with previous spontaneous dissections of the internal carotid arteries. Stroke 1985 16:959-963.

-6 Amarenco P, Seux-Levieil ML, Cohen A, Levy C, Touboul PJ, Bousser MG: Carotid artery dissection with renal infarcts: two cases. Stroke 1994;25:2488-2491.
7 Basso C, Morgagni GL, Thiene G: Spontaneous coronary artery dissection: a neglected cause of acute myocardial ischaemia and sudden death. Heart 1996;75:451-454.

-8 Brandt T, Grond-Ginsbach C: Spontaneous cervical artery dissection. From risk factors toward pathogenesis. Stroke 2002;33:657658.

-9 Tzourio C, Cohen A, Lamisse N, Biousse V, Bousser MG: Aortic root dilatation with spontaneous cervical artery dissection. Circulation 1997;95:2351-2353. 